\title{
Advanced, Soluble Hydroliquefaction and Hydrotreating Catalysts
}

MAY 11992

Annual Report No. 1

For the period August 7, 1990 through August 6, 1991

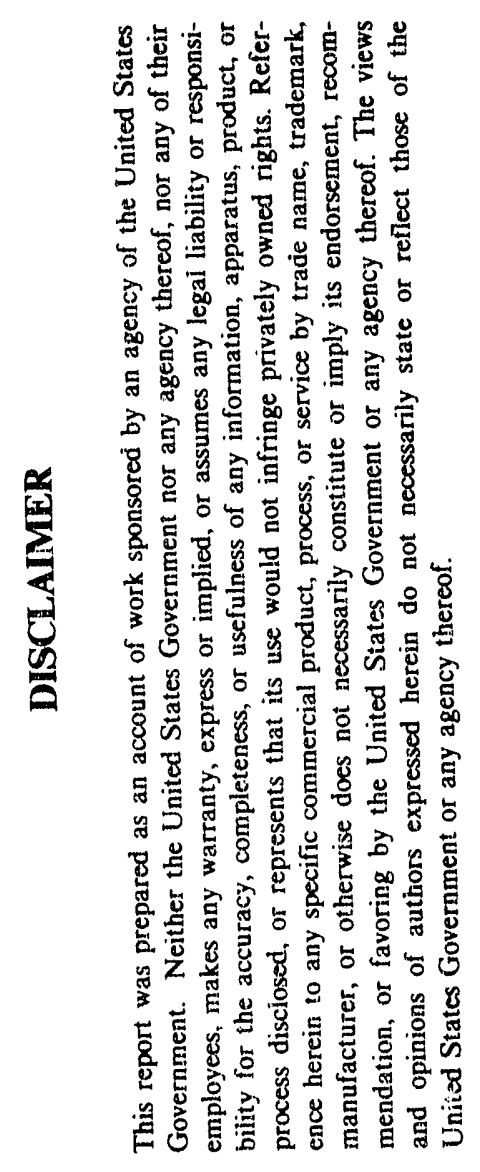

${ }^{a}$ Richard M. Laine, ${ }^{b}$ Thomas Stoebe

September 9, 1991

Work Preformed Under Contract No.

DE-FG22-90PC90313

a Department of Materials Science and Engineering

H. H. Dow Building, North Campus

University of Michigan

Ann Arbor, MI 48109-2136

$b_{\text {Department of Materials Science and Engineering }}$

Roberts Hall, FB-10

University of Washington

Seattle, WA 98195 


\section{DISCLAIMER}

This report was prepared as an account of work sponsored by the United States Government. Neither the United States nor the United States Department of Energy, nor any of their employees, make any warranty, express or implied, or assumes any legal liability or responsibility for the accuracy, completeness, or usefulness of any information, apparatus, product or process disclosed or represents that its use would not infringe privately owned rights. Reference herein to any specific commercial product, process, or service by trade name, mark, manufacturer, or otherwise, does not necessarily constitute or imply its endorsement, recommendation, or favoring by the United States Government or any agency thereof. The views and opinions of authors expressed herein do not necessarily state or reflect those of the United States Government or any agency thereof.

\section{PATENT STATUS}

This technical report is being transmitted in advance of DOE patent clearance and no further dissemination or publication shall be made of the report without prior approval of the DOE Patent Counsel

\section{TECHNICAL STATUS}

This technical report is being transmitted in advance of DOE review and no further dissemination of publication shall be made of the report without prior approval of the DOE Project/Program Manager 


\section{Introduction}

Present efforts to convert coal to fuels by direct hydroliquefaction suffer from being two stage direct processes, requiring high temperatures $\left(>400^{\circ} \mathrm{C}\right)$ and high hydrogen pressures $(\approx 2000$ psia $)$ to effectively convert coal to a liquid and then to synfuels or petrochemical feedstocks. The need for high $\mathrm{H}_{2}$ pressures results in excessive consumption of $\mathrm{H}_{2}$ and an over-hydrogenated (lower quality) product. For a synfuels from coal process to be economical, all facets of the process must be made as efficient as possible. Improved control of reaction temperatures, $\mathrm{H}_{2}$ pressures and consumption can provide significant improvements in efficiency and economy. All three areas are potentially controllable through careful selection of liquefaction catalysts.

Previous work in this group has shown that, surface confined, organometallic catalysts are exceptionally effective for hydrogenation and HDN of coal model compounds such as quinoline. ${ }^{1-6}$ Unfortunately, surface confined catalysts have not proven to be particularly effective when used with coal itself. The problem de ives from the fact that: (1) liquefaction is a solid (catalyst)-liquid (coal polymer) reaction system where, (2) diffusion of coal bonds to the heterogeneous catalyst surface is mass transport limited and controls liquefaction rates. Furthermore, heterogeneous catalyst mediated liquefaction is surface area dependent, placing another constraint on reaction rates.

The purpose of the present program is to develop soluble anaiogs of 'surface confined catalysts that can be impregnated directly into the coal structure at low temperatures. This approach should avoid problems related to surface area deper dence, a two phase (surface-liquid) reaction system and, mass transport limitations.

Heteropolyanions (HPAs) offer the opportunity to develop soluble forms of surface confined catalysts. HPAs, are inexpensive, well-characterized, water soluble metal oxide clusters, e.g. $\left[\mathrm{EM}_{12} \mathrm{O}_{40}\right]^{4-}$ where $\mathrm{E}=\mathrm{Si}$ or $\mathrm{P}$ and $\mathrm{M}=$ Mo or $\mathrm{W} .{ }^{7}$ They are easily modified to contain other transition metals such as $\mathrm{Co}, \mathrm{Ni}$ or Ru and, can be made soluble in organic solvents. ${ }^{7-9}$ The protic forms exhibit extremely high acidities $\mathrm{pK}_{\mathrm{a}} \approx 0-2 .^{7}$ In addition, selectively modified HPAs can function as low temperature hydrogenation catalysts that exhibit microporosity. ${ }^{10} \mathrm{HPAs}$ are multi-functional catalysts that could be used to promote both hydroliquefaction and hydrotreating. In theory, these functions could be employed sequentially or simultaneously and could permit exceptional control of liquefaction reactions and reaction conditions. Thus, the current research program involves efforts to evaluate HPAs as soluble liquefaction and hydrotreating catalysts, with the goal of developing soluble analogs of surface confined catalysts.

Alternately, if HPAs decompose under useful liquefaction conditions, we will explore the utility of creating bimetallic HPAs that can be impregnated into coal and then decomposed to give high surface area heterogeneous catalyst particles that may still permit us to accomplish the above described goals. 
The program consists of three major tasks: (1) Preparation of candidate HPA precatalysts; (2) HDN and HDO modeling studies and, (3) Direct liquefaction studies. The following sections outline the research planned in each area.

Task 1. Initially, we will prepare, according to literature procedure, a selected set of simple monometallic heteropolyanions (HPAs) that will screened in the Task 2 studies. Coincidentally, we will prepare more complex, bimetallic HPAs where the second metal is $\mathrm{Ni}$, Co or $\mathrm{Ru}$. We will prepare bimetallic HPAs wherein the cluster size, in terms of metal atoms, is varied as is the ratio of the two metals. We will also prepare trimetallic HPAs as the results in Tasks 2 and 3 warrant.

Task 2. The HPAs catalyst precursors prepared in Task 1 will be tested for HDN activities, selectivities, and $\mathrm{H}_{2}$ consumption using quinoline as a model substrate. Solvent will be hexadecane and/or $\mathrm{H}_{2} \mathrm{O}$. We will further evaluate those catalysts found to have superior activity by conducting in-depth rate studies to optimize reaction conditions as a prelude to exploring their use in Task 3.

Task 3. Initially, we will test the efficiencies of selected monometallic and bimetallic HPAs to assess the value of the Task 2 screening studies. Superior HPAs will be tested for ability to promote Wyodak 2 liquefaction and to upgrade the resultant coal liquids. The effects of pressure, solvent, reducing system $\left(\mathrm{H}_{2}\right.$ of $\left.\mathrm{CO} / \mathrm{H}_{2} \mathrm{O}\right)$ and temperatures on conversions, $\mathrm{H}_{2}$ consumption and the quality of the coal liquids will be used to evaluate catalyst ability.

\section{PROGRESS TO DATE}

In the first year, efforts were directed towards furnishing a coal laboratory, staffing and ordering equipment and initiating a research program.

Because of a hiatus in research due to the move of Richard M. Laine from the University of Washington to the University of Michigan, progress in the first three quarters of the first year were slow. In the fourth quarter, the first detailed efforts were made to study selected HPAs as low-temperature (below $225^{\circ} \mathrm{C}$ ) hydrogenation cataysts for the selective conversion of quinoline $(\mathbf{Q})$ to tetrahydroquinoline (T'HQ). In particular, baseline studies were conducted with simple Mo- and WHPAs to establish standard reaction parameters that perrnit detailed assessment of the potential of novel bimetallic HPA catalysts and precatalysts.

As will be discussed in the following sections, we have determined that Mo-HPA outperforms both W-HPA, a Co/Mo bimetallic HPA precatalyst, and selected simple metal oxide precatalysts, except ammonium heptamolybdate, under the hydrogenation conditions chosen. A simple bimetallic Mo-HPA/Ru precatalyst system outperforms the individual Mo-HPA and Ru precatalysts by functioning in what appears to be a synergistic manner. 
In addition, we find that under the catalysis conditions chosen, the initially homogeneous precatalyst solutions are transformed into an active heterogenous form. Results indicate that catalyst activity can be directly related to initial precatalyst solution concentration. It is concluded that the active heterogeneous catalyst has exceptionally high surface area as evidenced by the very fine particles sizes observed in scanning electron micrographs.

\section{Experimental_Section}

General Methods. Quinoline $(\mathbf{Q})$ was purchased from Aldrich and distilled from $\mathrm{CaH}_{2}$ under $\mathrm{N}_{2}$ before use. Absolute ethanol was used as received. Molybdophosphoric acid $\left(\mathrm{H}_{3} \mathrm{PO}_{4} \cdot 12 \mathrm{MoO}_{3} \cdot \mathrm{H}_{2} \mathrm{O} \equiv\right.$ $\mathrm{H}_{3} \mathrm{PMo}_{12} \mathrm{O}_{40} \cdot \times \mathrm{H}_{2} \mathrm{O}$, Mo-HPA) was purchased from Strem Chemicals and used as received. $\mathrm{RuCl}_{3} \cdot \mathrm{xH}_{2} \mathrm{O}$ $(x=1-3)$ was obtained from Johnson Matthey Electronics and stored in a Dri-Box under $\mathrm{N}_{2}$. Stoplight compound, $\left(\mathrm{NH}_{4}\right)_{6}\left[\mathrm{Co}_{2} \mathrm{Mo}_{10} \mathrm{O}_{38} \mathrm{H}_{4}\right] \cdot 7 \mathrm{H}_{2} \mathrm{O}$, was prepared as described previously. ${ }^{11}$ Phosphotungstic acid $\left(\mathrm{H}_{3} \mathrm{PW}_{12} \mathrm{O}_{40} \times \mathrm{H}_{2} \mathrm{O}\right.$, W-HPA), ammonium metavanadate $\left(\mathrm{NH}_{4} \mathrm{VO}_{3}\right)$, and ammonium heptamolybdate $\left[\left(\mathrm{NH}_{4}\right)_{6} \mathrm{Mo}_{7} \mathrm{O}_{24} \cdot 4 \mathrm{H}_{2} \mathrm{O}\right]$ were purchased from Aidrich, British Drug House Ltd., and Allied Chemical Company, respectively and used as received.

Analytical Procedures. Product analyses for all the kinetic studies were performed on a temperature programmed ${ }^{12}$ Hewlett-Packard 5890 A reporting GC equipped with FID using a $5 \mathrm{~m} \mathrm{x} 0.53 \mathrm{~mm} \times$ $2.65 \mu \mathrm{m}$ capillary column packed with $100 \%$ dimethyl polysiloxane gum.

General Reaction Procedures for Kinetic Studies. Stock solutions of Mo-HPA were prepared before use by dissolving $0.1 \mathrm{~g}\left(5.5 \times 10^{-2} \mathrm{mmol}\right)$ of molybdophosphoric acid (Mo-HP $\left.\mathrm{s}\right)$ in $50 \mathrm{~mL}$ of ethanol to form a $1.1 \times 10^{-3} \mathrm{M}$ solution. In a typical reaction, an amount of stock solution (e.g. $5 \mathrm{~mL}$ ) containing up to $5.5 \times 10^{-3} \mathrm{mmol}$ of Mo-HPA or other catalyst precursor and $5 \mathrm{~mL}$ ( $42.3 \mathrm{mmol}$ ) of quinoline $(\mathrm{Q})$ were placed in a magnetically stirred, 34-mL quartz lined bomb reactor with $50 \mu \mathrm{L}$ of $\mathrm{CS}_{2}$. The reactor was sealed and degassed via three pressurization/depressurization cycles using 800 psig $\mathrm{N}_{2}$ and $\mathrm{H}_{2}$ and then pressurized to the desired pressure with $\mathrm{H}_{2}$. The reactor was heated in an oil bath thermostatted to $\pm 2{ }^{\circ} \mathrm{C}$ of the appropriate temperature, and samples were taken at selected times by cooling the reactor in cold water bath, depressurizing, and removing a $0.1-\mathrm{mL}$ sample. The reaction was then restarted following the above procedure. In all of the experiments dusuribed throughout the paper, the reported $\mathrm{H}_{2}$ gas pressures are presented as psig, at room temperature.

Procedure A. In the $\mathrm{H}_{2}$ pressure and temperature studies, $5 \mathrm{mI}$ of the stock Mo-HPA solution and $5 \mathrm{~mL}(42.3 \mathrm{mmol})$ of $\mathrm{Q}$ were used with $50 \mu \mathrm{L}$ of $\mathrm{CS}_{2}$.

Procedure B. A slightly modified version of Procedure A was used to explore the effects of variations in Mo-HPA and Q concentrations on $Q$ hydrogenation rates. In the se studies, the amount of catalyst or $\mathrm{Q}$ added for each set was varied over a selected range of concentrations as discussed below.

Procedure $\mathrm{C}$. In these experiments, the required quantities of precatalyst were weighed in air except 
$\mathrm{RuCl}_{3} \cdot \mathrm{xH}_{2} \mathrm{O}$ and transferred to a quartz-lined reactor.

Catalyst Activity. In all instances, catalyst activity is measured as a function of the turnover frequency (TF). TF is defined as: No. moles of product (tetrahydroquinoline, THQ)/total moles of metal (not moles of precatalyst)/ hour. Activities were always determined based on less than $25 \%$ conversion of $Q$ to THQ. Thus, no falloff effects were included in theTF calculations.

$\mathrm{H}_{2}$ Pressure Studies. These reactions were run according to procedure A. The reactor was charged with $\mathrm{H}_{2}$ gas using pressures from 0 to $1000 \mathrm{psig}$ (at room temperature). The reaction temperature was held constant at $200^{\circ} \mathrm{C}$.

Catalyst Concentration Studies. Reactions were run as described for procedure B. Experiments were conducted in ethanol using initial $\mathrm{H}_{2}$ pressures of $600 \mathrm{psig}$. The reaction temperature was held constant at $200^{\circ} \mathrm{C}$. Mo-HPA concentrations were varied between $1.1 \times 10^{-4} \mathrm{M}$ and $5.5 \times 10^{-4} \mathrm{M}$ with total reaction volumes maintained constant at $10 \mathrm{~mL}$. Typically, a known volume (e.g. $1.0 \mathrm{~mL}$ ) of the stock solution was syringed into the reactor, followed by sufficient pure ethanol $(4.0 \mathrm{ml})$ to maintain constant solvent volume and then $5.0 \mathrm{~mL}$ of $\mathrm{Q}$.

Quinoline Concentration Studues. Reactions were run as in the catalyst concentration studies with the exception that the concentration of Mo-HPA was held constant at $5.5 \times 10^{-4} \mathrm{M}$. Q concentrations were varied from 0.85 to $7.62 \mathrm{M}$. In these instances, additional ethanol was added to maintain a $10 \mathrm{~mL}$ reaction volume.

Temperature Studies. Reactions were run as in the $\mathrm{H}_{2}$ pressure studies with the exception that the initial $\mathrm{H}_{2}$ pressure was held constant at $400 \mathrm{psig}$. Rates were recorded at $150,175,200$, and $225^{\circ} \mathrm{C}$, the range bounded at low temperature by minimal catalyst activity and at the upper temperature by the flammabilty/decomposition temperature of the oil baths $\left(\approx 250^{\circ} \mathrm{C}\right)$.

Catalyst Precursor Survey. A series of potential HPA hydrotreating catalysts were tested for Q hydrogenation activity. The catalysts were surveyed using the following procedures. Reactions were run at constant $\mathrm{H}_{2}$ pressure (400 psig $\mathrm{H}_{2}$ at room temperature) at $175^{\circ} \mathrm{C}$ as described for procedure $\mathrm{C}$. Concentrations of catalyst were $5.5 \times 10^{-4} \mathrm{M}$ in Mo-HPA, $6.5 \times 10^{-5} \mathrm{M}$ for W-HPA, $1.1 \times 10^{-2} \mathrm{M}$ for $\left(\mathrm{NH}_{4}\right) \mathrm{VO}_{3}, 1.5 \times 10^{-4} \mathrm{M}$ for $\left(\mathrm{NH}_{4}\right)_{6} \mathrm{Mo}_{7} \mathrm{O}_{24} \times \mathrm{H}_{2} \mathrm{O}$, and $1.8 \times 10^{-3} \mathrm{M}$ in stoplight compound. The stock solution of $\mathrm{RuCl}_{3} \cdot \mathrm{xH}_{2} \mathrm{O}$ was prepared by dissolving $0.03 \mathrm{~g}(0.11 \mathrm{mmoles})$ of solid in $20 \mathrm{~mL}$. of dry ethanol under $\mathrm{N}_{2}$ atmosphere and $5 \mathrm{~mL}$ of the stock solution $\left(5.7 \times 10^{-3} \mathrm{M}\right)$ was used for the reaction. $\mathrm{Mo}-\mathrm{HPA} / \mathrm{RuCl}_{3}$ catalyst precursor was prepared by mixing $0.05 \mathrm{~mL}\left(5.7 \times 10^{-3} \mathrm{M}, 2.87 \times 10^{-4} \mathrm{mmol}\right)$ of $\mathrm{RuCl}_{3} \times \mathrm{xH}_{2} \mathrm{O}$ stock solution with $5 \mathrm{~mL}$ of ethanol solution of $5.7 \times 10^{-3} \mathrm{M}$ in Mo-HPA $\left(5.5 \times 10^{-4} \mathrm{mmol}\right)$.

Solvent Effect Studies. Only acetonitrile was found to be useful for dissolution of Mo-HPA and was used in place of ethanol in this study. The reaction was run as in the $\mathrm{H}_{2}$ pressure studies (procedure 6 
A) at 600 psig $\mathrm{H}_{2}$ (measured at room temperature) and $200^{\circ} \mathrm{C}$.

Scanning Electron Micrograph (SEM) Studies. SEM micrographs taken of the active catalyst produced when procedure $A$ is run using two conditions (sample $1 ; 600 \mathrm{psi}_{2}, 200^{\circ} \mathrm{C}, 6$ hours and sample 2; 450 psi $\mathrm{H}_{2}, 200^{\circ} \mathrm{C}, 11$ hours) were recorded on a Hitachi Model S-520 scanning electron microscope. Sample 1 was aged for 56 days in air and sample 2 was fresh when SEM was taken. These micrographs are shown in Figures 7,7A for sample 1 and 8, 8A for sample 2, respectively.

\section{Results}

$\mathrm{H}_{2}$ Pressure Studies. The effects of variations in $\mathrm{H}_{2}$ pressure $\left(\mathrm{P}_{\mathrm{H} 2}\right)$ on catalyst activity are shown in Figure 1. Within the limits of the current studies, there appears to be an almost linear relationship between $\mathrm{H}_{2}$ pressure and catalyst activity (turnover frequency, TF). In the absence of $\mathrm{H}_{2}$, no catalyst activity is observed for a procedure A reaction solution, even following 27 hours heating at $200^{\circ} \mathrm{C}$. These results were anticipated from the fact that $\mathrm{H}_{2}$ is necessary for the reduction, sulfidation and transformation of the homogeneous catalyst percursor into the active catalyst. Under the conditions studied, it was not possible to ascertain the $\mathrm{P}_{\mathrm{H} 2}$ required to reach the falloff region, where the relationship TF/P $\mathrm{H}_{2}$ is no longer linear.

Precatalyst Concentration Studies. Figure 2 shows the effect of total metal concentration on catalyst activity. The highest catalyst concentration used in this study $\left(5.5 \times 10^{-4} \mathrm{M}\right)$ is less than 0.02 mole $\%$ of the $\mathrm{Q}$ concentration used. Within the range of catalyst concentrations studied, except at very low concentrations, there appears to be a linear relationship between catalyst concentration and TF. These results are extremely valuable because, as we will discuss below, the active catalyst is heterogeneous.

Quinoline Concentration Studies. The results shown in Figure 3 indicate that under the reaction conditions studied, the rate of $\mathrm{Q}$ hydrogenation to $\mathrm{THQ}$ is not linearly dependent on initial $\mathrm{Q}$ concentration. The turnover frequency reaches its maximum $(\mathrm{TF}=20)$ at $[\mathrm{Q}]=4.23 \mathrm{M}$ at $[\mathrm{Mo}-\mathrm{HPA}]=5.5 \times 10^{-4} \mathrm{M}$. Considering the extremely high [Q] concentrations used, there are three likely explanations for the observed falloff. One is that above $[Q]=4.23 \mathrm{M}$, the reaction conditions are pseudo first order, with $\mathrm{H}_{2}$ pressure being the only variable and the falloff above these concentrations resulting from experimental error. Alternately, at these high concentrations, $Q$ competes successfully with $\mathrm{H}_{2}$ for active catalyst sites thereby slowling the rate of hydrogenation. The third explanation is that at these high $\mathrm{Q}$ concentrations, the composition of the reaction solution is considerably changed--there is much less EtOH. Consequently, the solubility or the solvation of the precatalyst changes and the surface area of the active catalyst produced is diminished thereby reducing overall catalyst activity.

Temperature Studies. Initial rates of reaction were determined for each temperature from 150 to $225^{\circ} \mathrm{C}$ using the reaction conditions described for procedure $\mathrm{A}$ in the experimental section with initial $\mathrm{H}_{2}$ 


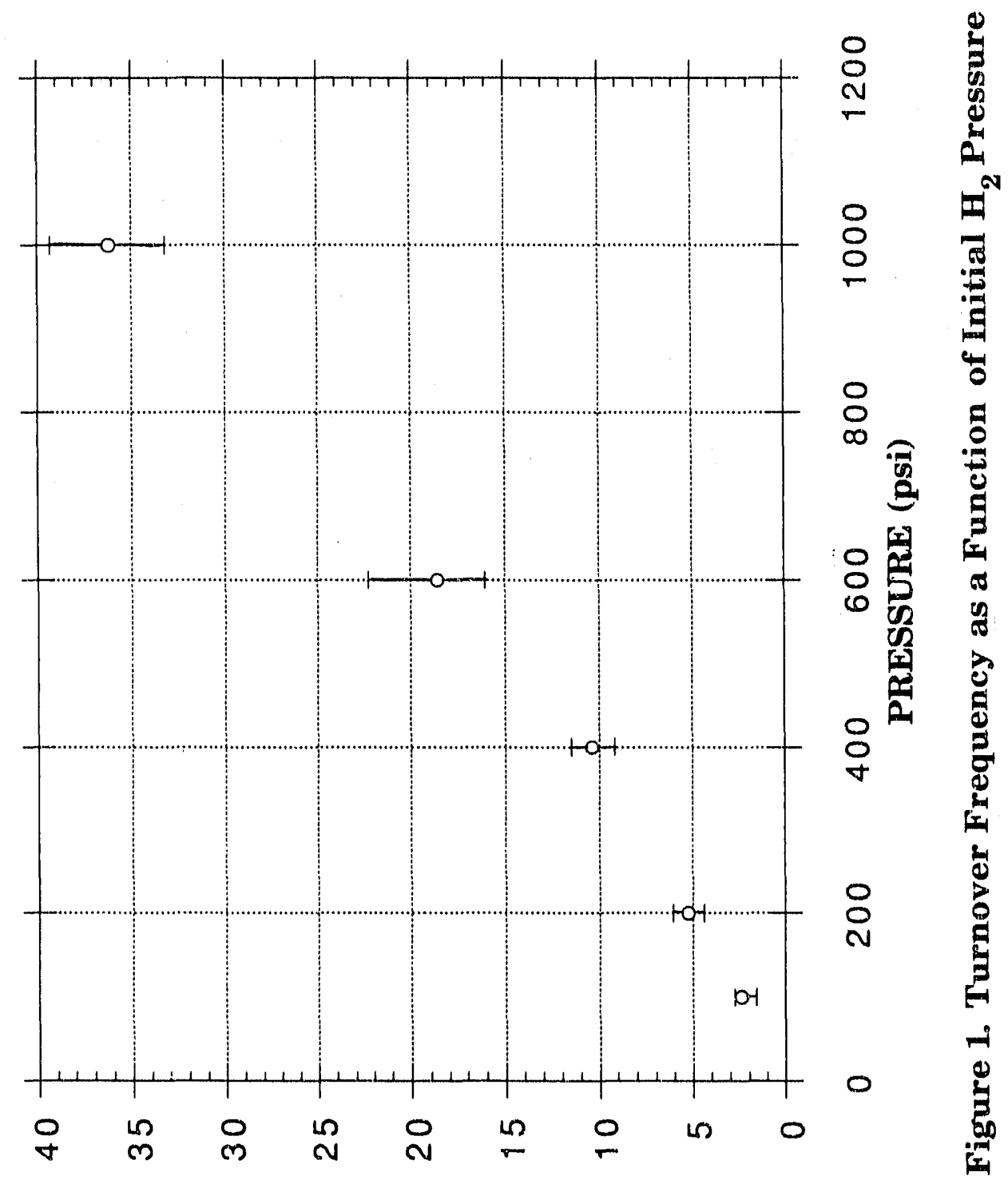

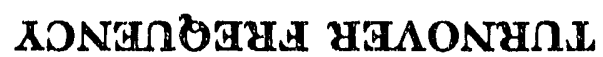




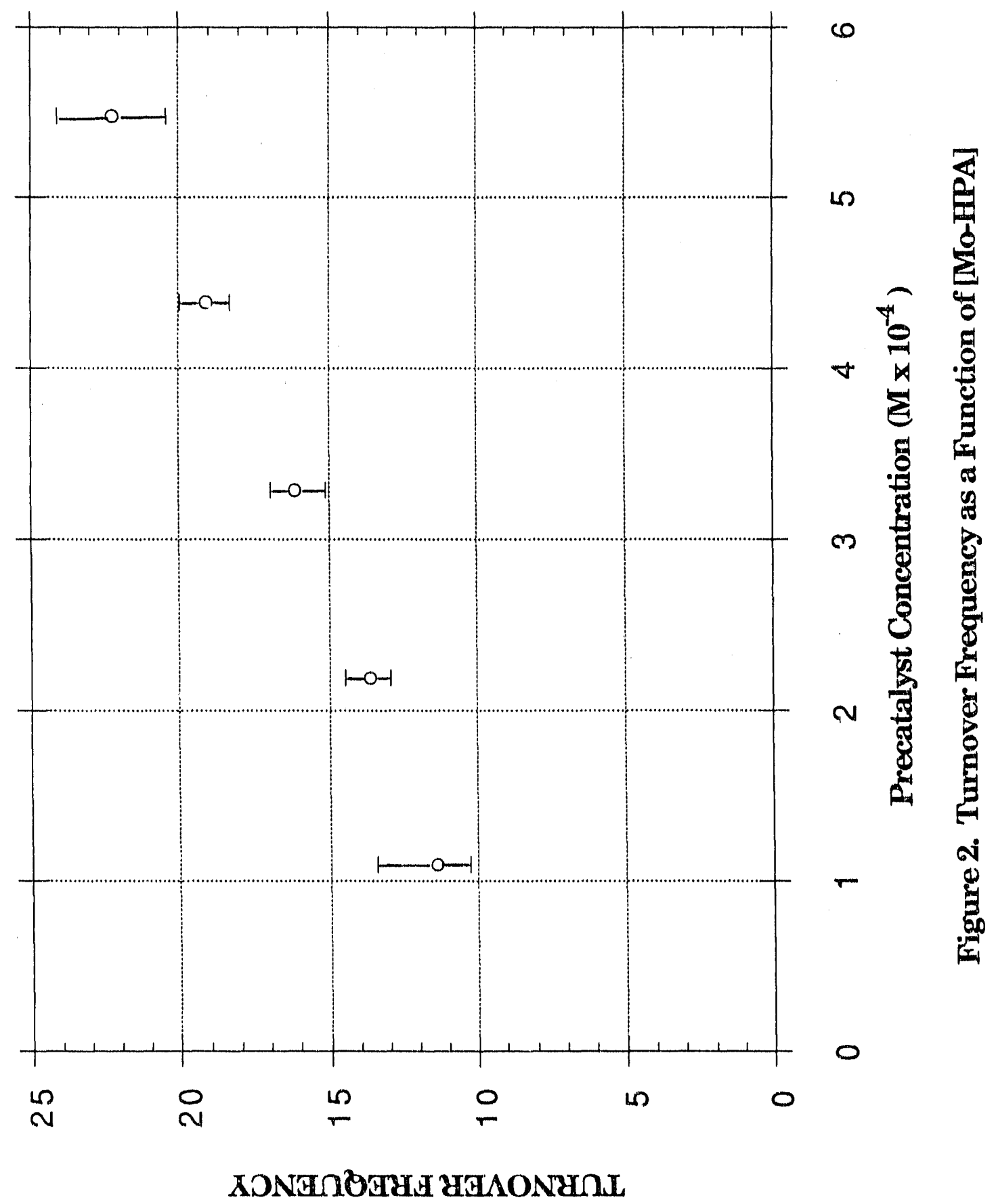




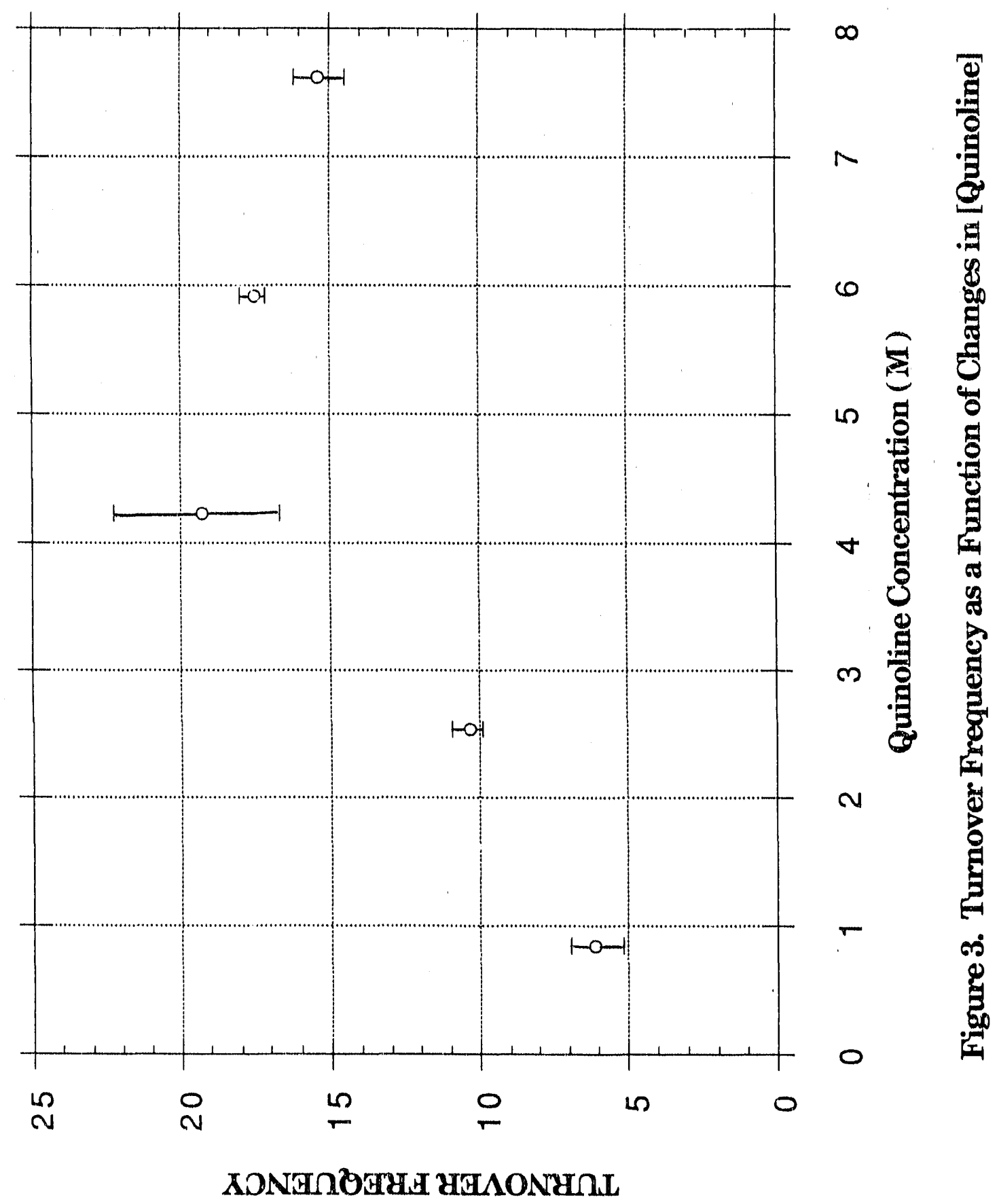




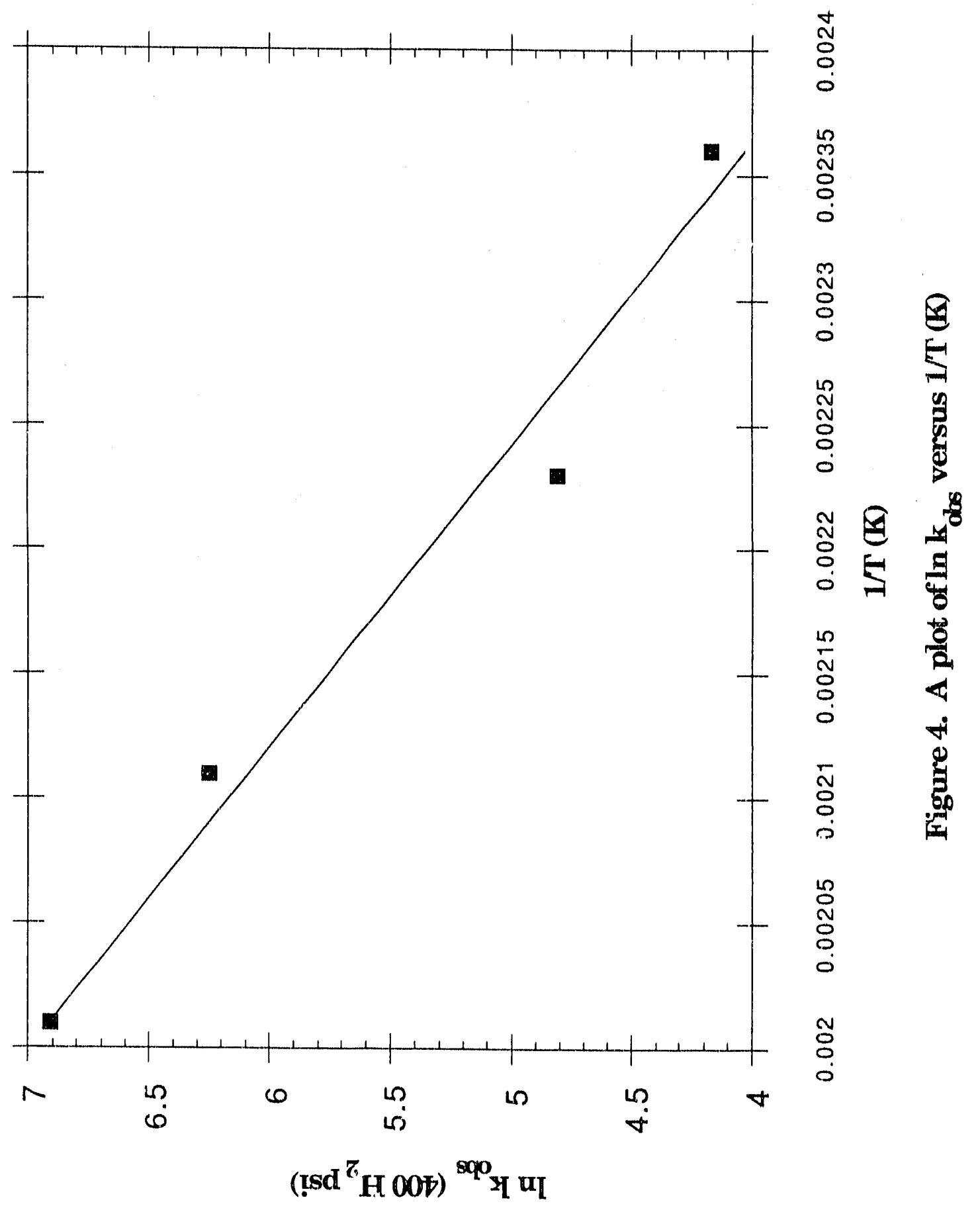


pressures of $400 \mathrm{psig}$. Raw reaction rate data are used to calculate initial TFs which are used as $\mathrm{k}_{\mathrm{obs}}$ in (Figure 4). ${ }^{13}$ These data allow us to calculate the energy of activation, $E_{a}=16.4 \pm 3 \mathrm{kcal} / \mathrm{mole}$.

Catalyst Activity Studies. As shown in Figure 5, the bimetallic Mo-HPA/RuCl $3 \cdot \mathrm{xH}_{2} \mathrm{O}$ precatalyst system exhibits the highest catalyst activity (TF 10) among the precatalysts surveyed. However, the absence of catalytic activity for W-HPA and $\left(\mathrm{NH}_{4}\right) \mathrm{VO}_{3}$ were somewhat unexpected considering the modest activities of the polyoxomolybdate catalysts. It is also somewhat surprising that $\mathrm{RuCl}_{3} \cdot \mathrm{xH}_{2} \mathrm{O}$ alone displays such good Q hydrogenation activity (even better than Mo-HPA) as shown in Figure 6. Ruthenium was originally chosen for catalytic studies predicated on its extremely good C-N and C-C bond hydrogenolysis activities as determined in our previous efforts, ${ }^{1-6}$ those of Massoth et al, ${ }^{14}$ Chianelli et al. ${ }^{15,16}$ and, Harvey and Matheson. ${ }^{17}$

Solvent Effect studies. Two solvents (ethanol and acetonitrile) were used in this study. In EtOH, only THQ was obtained as a product. In acetonitrile, two products are observed, THQ and $\mathrm{C}_{2} \mathrm{H}_{5}-\mathrm{THQ}$. The Et-THQ must arise by cleavage of the $\mathrm{C}-\mathrm{N}$ triple bond in $\mathrm{CH}_{3} \mathrm{CN}$ during the hydrogenation of $\mathrm{Q}$.

\section{Discussion}

The baseline studies described in the results section were conducted to: (1) develop a set of standard conditions for testing HPA precatalyst systems; (2) identify, under minimum catalyst activity conditions, promising systems for further study at higher temperatures, and (3) establish hydrogenation reactivity patterns of the prospective catalyst systems. These studies were designed to answer several important questions concerning the utility of HPAs as hydrotreating and hydroliquefaction precatalysts. The questions include: (1) Do HPA derived catalysts function as heterogeneous or homogeneous catalysts; (2) What advantages do HPAs offer over conventional catalysts; (3) Are polymetallic HPA derived catalysts better than conventional or monometallic HPA catalysts, and (4) Do the modeling studies reflect what is observed during coal liquefaction.

Minimum activity studies are catalyst activity studies wherein the reaction conditions are far from optimum. As such, many catalysts will show limited or no activity for the reaction being studied and only good to exceptional catalysts will show moderate activity. The results of such screening studies provide an immediate focus for more detailed optimization studies.

\section{How Do HPA Derived Catalysts Function}

In the original proposal, we indicated that degradation of the homogeneous HPA systems was a possiblity that could only be ascertained by experimentation. We find that HPA systems do indeed produce heterogeneous catalysts; however, the initial results rather than being discouraging are quite promising. Proof of heterogeneity comes from the fact that catalyst activation requires: (1) hydrogen reduction; (2) the presence of sulfur, and (3) an induction period $\left(10-15 \mathrm{~min}\right.$ at $\left.200^{\circ} \mathrm{C}\right)$ prior to onset of catalyst activity. 


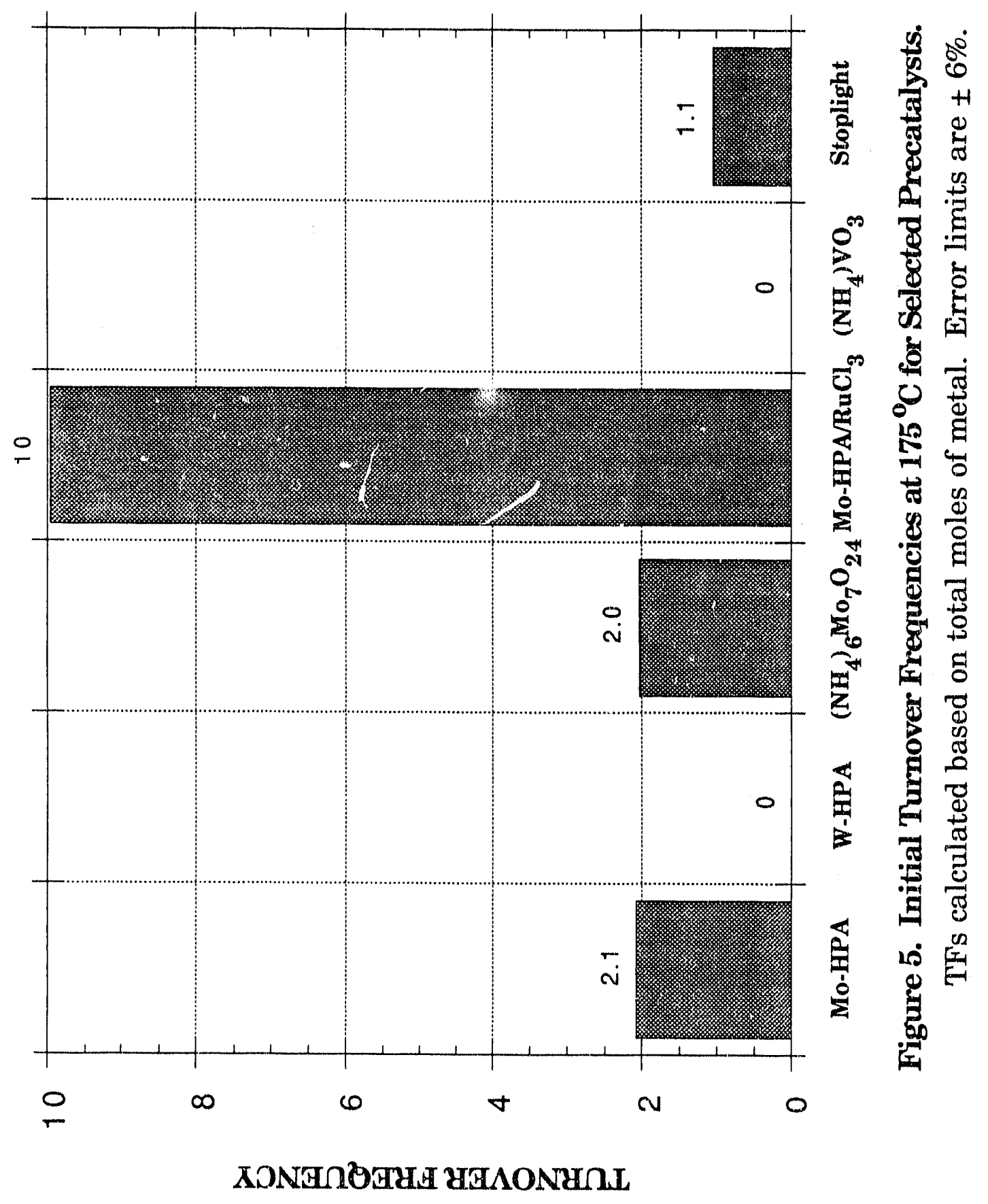




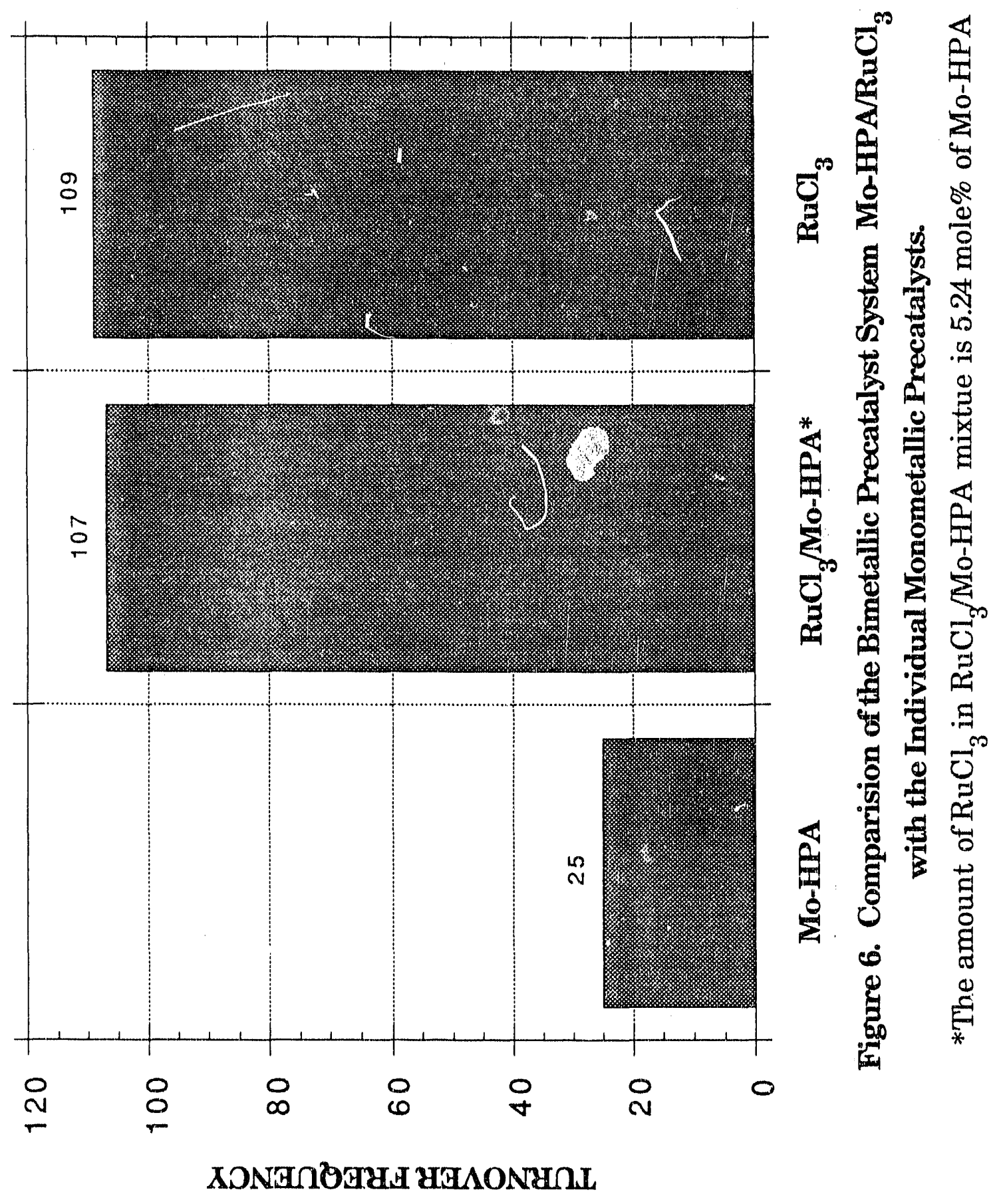


Without any one of these components, catalyst activation is not obtained. In addition, once the heterogeneous catalyst has been formed, removal of all of the reaction solution (by decantation in air) followed by readdition of nore $\mathrm{Q}$ and $\mathrm{EtOH}$ (but not $\mathrm{CS}_{2}$ ) and repressurization to the previous starting $\mathrm{H}_{2}$ pressure, gives the same catalyst activity as that obtained initially--without an induction period.

Thus, the heterogeneous material formed by reduction, sulfidation and degradation of the HPAs is the true, active catalyst. One positive point about this system is that the active catalyst retains its initial activity after cycling and exposure to air. A second point comes from the observation that there is a direct and linear correlation between precatalyst concentration and catalyst activity (Figure 2). This linear relationship is observed despite the fact that catalysis occurs after conversion of the homogeneous precatalyst to the active, heterogeneous form.

It can be argued that increases in precatalyst concentration should lead to lower, , elative catalyst surface areas (leading to lower TF/mole metal) as initially nucleated catalyst particles serve as growth sites for the decomposition of additional HPA molecules. Given that the correlation is linear, we presume that nucleation is a solution phase rather than a surface phenomena. Thus, all of the catalyst particles should be of approximately the same dimensions. The SEMs shown in Figures 7 and 8 support this idea given that the fresh catalyst particles, seen at highest magnification, are submicro:? and therefore offer very high surface areas.

These results are important for several reasons. First, size reproducibility in the generation of active catalyst particles from solution should be relatively facile. Second, it may be possible to control the catalyst particle size by developing an understanding of the kinetics and mechanisms of particle formation. This in turn may permit one to optimize particl . size/catalyst activities. Finally, it may be possible to control many aspects of catalyst activity during HPA impregnation and activation in coal.

\section{What Advantages Do HPAs Offer Over Conventional Catalysts}

There are several potential advantages offered by HPAs relative to conventional catalysts. First, HPAs are soluble in a variety of polar and slightly polar solvents including water, $\mathrm{MeOH}, \mathrm{EtOH}$, and acetonitrile. Consequently, under liquefaction conditions, it should be possible to tailor the HPA/solvent system to optimize coal swelling and coincidentally catalyst dispersion. By comparison, conventional soluble catalysts such as ammonium heptamolybdate; which exhibits essentially the same activity as Mo-HPA (see Figure 5 ), is soluble only in water.

Conventional heterogeneous bimetallic catalysts are often used effectively for coal liquefaction and subsequent hydrotreating. Unfortunately, these systems are not amenable to impregnation which means that their proven catalytic advantages over monometallic systems cannot be used effectively. One approach that is potentially employable is double impregnation with two different metals either simultaneously or 


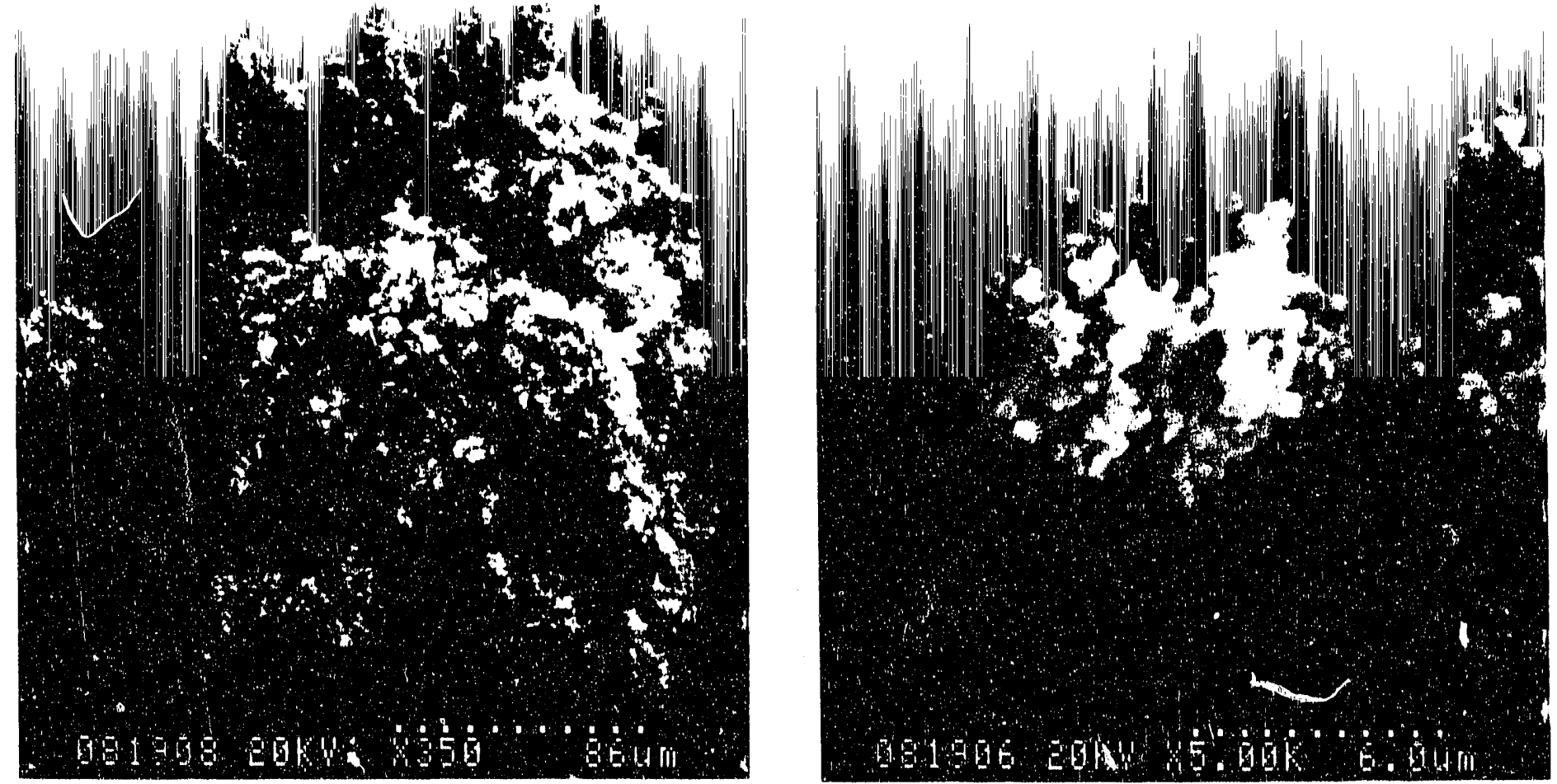

Figure 7. SEM Micrograph Picture of Sample 1 (Magnification; X 350, Fresh catalyst)

Figure 7A. SEM Micrograph Picture of Sample 1 (Magnification; X 5.0 K, Fresh catalyst)
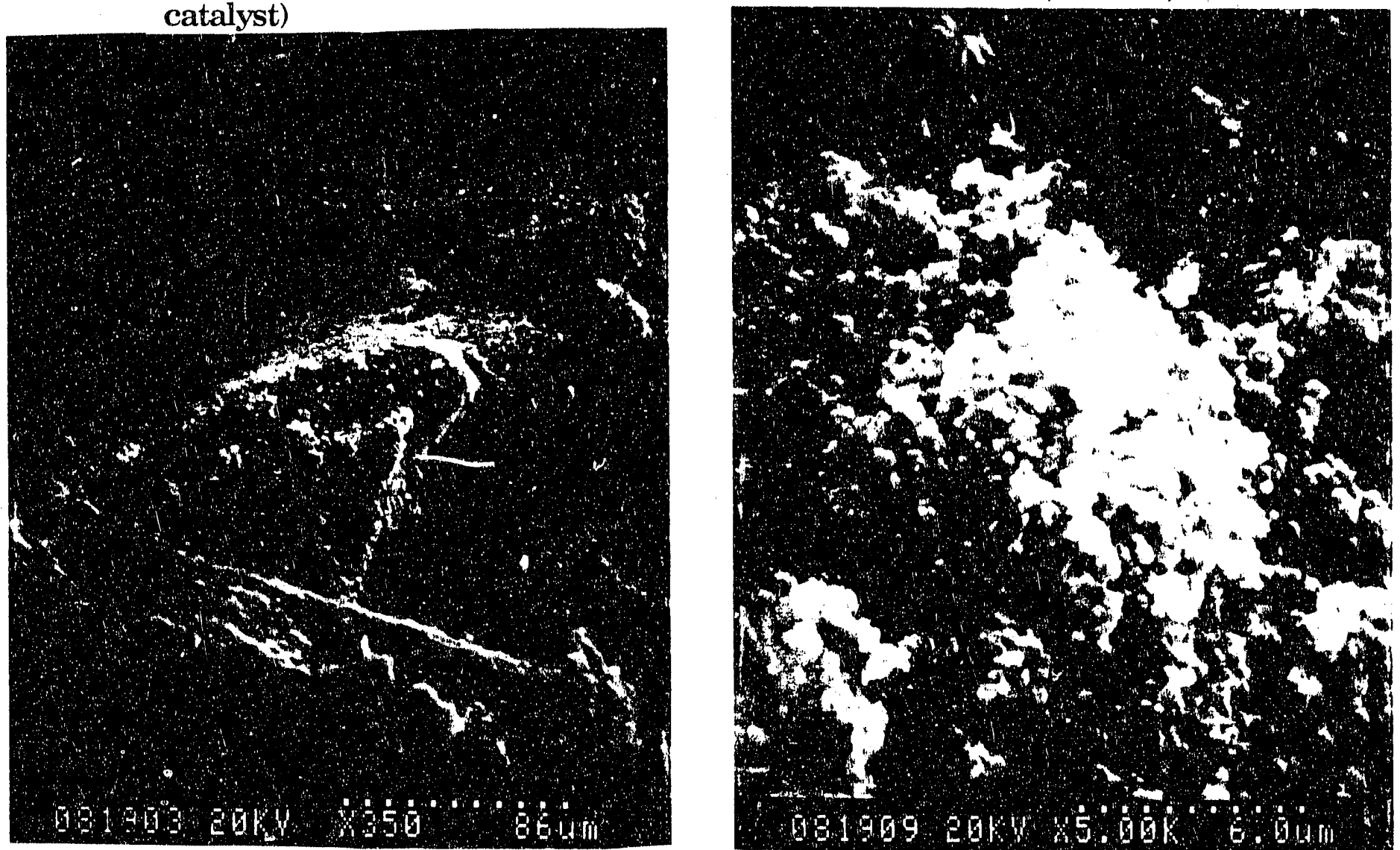

Figure 8. SEM Micrograph Picture of Sample 2 (Magnification; X 350, Aged catalyst)

Figure 8A. SEM Micrograph Picture of Sample 2 (Magnification; X 5.0 K, Aged catalyst) 
consecutively. One likely drawback is that because of different coal/metal affinities, it will not be possible to conveniently control the exact metal:metal ratios and dispersities necessary to cbtain optimal bimetallic catalytic activities in the coal.

Bimetallic HPAs, which offer direct control of the ratios of the two metals, should provide a method of surmounting this problem. Surprisingly, the survey results with the bimetallic "stoplight" precatalyst, $\left(\mathrm{NH}_{4}\right)_{6}\left[\mathrm{Co}_{2} \mathrm{Mo}_{10} \mathrm{O}_{38} \mathrm{H}_{4}\right] \cdot 7 \mathrm{H}_{2} \mathrm{O}$ reveal a catalyst activity that is somewhat less than that exhibited by MoHPA and the heptamolybdate on a per-mol of metal basis. The most likely explanation for this is that the effectiveness of bimetallic catalysts such as "CoMo" and NiMo" derives from their ability to effect C-N bond hydrogenolysis rather than hydrogenation of Q to THQ. Indeed, one could argue from our data on Mo-HPA, Stoplight, and the heptamolybdate that hydrogenation of Q must occur almost entirely on sulfided molybdenum sites. The stoplight compound, ${ }^{1}$ with some cobalt should generate catalyst particles with some portion of the surface "protected" by cobalt. Consequently, if sulfided molybdenum sites are indeed responsible for hydrogenation, one would expect the stoplight derived catalyst to exhibit lower TFs for Q hydrogenation, as observed. An alternate explanation is that the dccomposition pattern for the stoplight compound is different from that of Mo-HPA. This represents an area of future study.

\section{Polymetallic HPA Precatalysts vs Conventional or Monometallic HPA Precatalysts}

If we were only to compare the catalytic efficiencies of Mo-HPA, Stoplight, and the heptamolybdate as catalysts for the hydrogenation of $\mathrm{Q}$ to THQ, then we could argue that there is no obvious difference and further investigation is not warranted. Alternately, a more valid criticism would be that we have chosen the wrong reaction conditions to test catalytic activity. That is, we should also develop standard tests for HDN catalysis. Indeed these rests will be developed in the next year as noted in the section on Future work.

Fortunately, we have conducted one set of tests based on our previous discovery that RuMo bimetallic systems were exceptionally active HDN systems. ${ }^{2}$ Our previous studies were conducted with the objective of optimizing $\mathrm{Ru} / \mathrm{CoMo} / \alpha$-alumina catalysts for the HDN of $\mathrm{Q}$ to propylbenzene. ${ }^{2}$ It was assumed that the major function of the ruthenium in this trimetallic system was to promote $\mathrm{C}-\mathrm{N}$ bond cleavage at extremely low temperatures. No efforts were made to determine the effects of ruthenium on the individual metils (Co and $\mathrm{Mo}$ ) or the effects of the alumina support on the overall activity of the catalysts. Furthermore, no effort was made to explore the effects of Ru on the hydrogenation activity of this catalyst system.

We have begun to assess all of these variables here to establish a more detailed understanding of the effects of Ru both on hydrogenation and HLN as a prelude to developing Ru-HPAs. As can be seen in Figure 6, the use of a soluble $\mathrm{Ru}$ catalyst (as $\mathrm{RuCl}_{3} \cdot \mathrm{xH}_{2} \mathrm{O}$ ) alone provides an exceptional heterogeneous hydrogenation catalyst. However, what is considerably more surprising is that simple mixtures of the soluble $\mathrm{Ru}$ catalyst with Mo-HPA, where the Ru content is $\approx 5$ mole percent of the total Mo content, provide a catalyst systern that is just as effective as the pure Ru catalyst and four times as effective as the simple 
Mo-HPA catalyst. The results clearly point to a synergistic system. It is too early to speculate on the reasons for these results; however, it is clear that an alumina support is not necessary to promote the hydrogenation reaction; although, it may have some effect on long-term catalyst activity.

Hydrogenation Modeling Studies vs HDN Activity vs. Coal Liquefaction Behavior.

The RuMo catalyst, which shows exceptional activity for Q to THQ conversion, was explored based on the exceptional abilities of a supported RuMo material to promote THQ HDN catalysis as previously reported from these laboratories. ${ }^{1-6}$ Although it is tempting to claim that the hydrogenation activities parallel the previously determined HDN (C-N bond hydrogenolysis) activities, we believe that the parallel is coincidental. For example, both $\mathrm{Rh}$ and $\mathrm{Pd}$ catalysts are quite effective as hydrogenation catalysts but exhibit only moderate HDN activity. ${ }^{18,19}$

The use of a Ru/Mo-HPA bimetallic system in the hydrogenation studies reported above appears to work well and will be pursued in greater detail in the future; however, this system can only serve usefully as a baseline because of the method of catalyst preparation. Because hydrogenation catalysis begins with homogeneous precatalysts, it was possible to prepare a precatalyst system that consists of soluble forms of both $\mathrm{Ru}$ and Mo. In direct liquefaction studies, a major concern (see above) will be our ability to achieve the same bimetallic catalyst properties by impregnation of coal with the two independent, soluble species. Thus, it is clear that efforts must be directed towards the development of Ru/Mo-HPAs both for contrast purposes in the solution phase studies and for the direct liquefaction studies

\section{Future Work}

Although several details and questions remain unanswered; as discussed above, the current studies provide boundary conditions for studies on other model compounds including sulfur containing species and planned studies with coal. They also point to the need for complementary modeling studies on HDN of THQ to propylbenzene and propylcyclohexane.

For example, such studies are necessary to avoid ignoring HPAs already studied, ie. W-HPA, should they offer exceptional HDN activity. In such an event, one could envision developing trimetallic HPAs that serve as multifunctional catalysts. One metal or two doing hydrogenation and the remaining metallic species promoting HDN.

Now that the baseline, minimum activity parameters for testing HPAs have been worked out for hydro-" genation of Q to THQ, we will begin synthesizing other HPAs (see original proposal for details) to test in the survey reaction. We will simultaneously begin to develop an HDN model reaction to continue the screening process. As we identifiy specific HPAs with exceptional properties for hydrogenation and/or HDN catalysis, we will begin efforts to liquefy coal. 
We have ordered Wyodak coal samples from the Argonne repository and plan to begin liquefaction studies in the sixth quarter. ${ }^{9}$ We have just drawn up plans for a heater system whereby the Parr autoclaves currently used, can be heated to $350^{\circ} \mathrm{C}$ so that minimum activity liquefaction studies can be performed. As with the model systems, it will be necessary to develop a screening process. We plan to use reaction conditions identified previously as a starting point. 1,6 


\section{References}

1. "New Catalysts for Hydrotreating Coal Liquids." A. S. Hirschon, R. B. Wilson Jr., and R. M. Laine, Am. Chem. Soc. Div. Fuel. Prepr. (1986) 31, 310-317.

2. "Modeling the Hydrodenitrogenation Reaction Using Homogeneous Catalyst Model Systems." A. S. Hirschon, R. B. Wilson, Jr.; and R. M. Laine, New J. Chem., (1987) 11, 543-547.

3. "New Approaches to Enhance Hydrodenitrogenation of Coal Liquids" A. S. Hirschon, R. B. Wilson, Jr., R. M. Laine, in Adv, in Coal Chemistry, Theophrastus Publ, Athens 1988, p 351.

4. "Ruthenium Promoted Hydrodenitrogenation Catalysts." A. S. Hirschon, R. B. Wilson Jr., and R. M. Laine, J. Appl. Cat. (1987) 34, 311-316.

5. "Bulk Ruthenium as an HDN Catalyst", A. S. Hirschon and R. M. Laine, J. Energy and Fuels (1988) 2, 292-295.

6. "Use of Promoters to Enhance Hydrodenitrogenation and Hydrodeoxygenation Catalysis", A. S. Hirschon, L. L. Ackerman, R. M. Laine, and R. B. Wilson, Jr. Proc. of the 1989 Internat. Conf. on Coal Science, Tokyo,. Vol. II, p. 923.

7. Heteropoly and Isopoly Oxometalates, M. T. Pope, Springer-Verlag Pub., Berlin, GDR 1983.

8. R. F. Renneke and C. L. Hill, J. Am. Chem. Soc., (1988) $110,5461$.

9. R. K.C. Ho, W. G. Klemperer, J. Am. Chem. Soc., (1978) $100,6774$.

10. A. R. Siedle, R. A. Newmark, M. R. V. Sahyun, P. A. Lyon, S. L. Hunt, and R. P. Skarjune, JACS (1989) 111, 8346.

11. G. Tsigdinos, Dissertation Abstract, University of Michigan, B22, 732 (1961)

12. The conditions for the GC heating program used in this study are: Initial temperature; $35^{\circ} \mathrm{C}$, initial time; $30 \mathrm{sec}$., final temperature; $180^{\circ} \mathrm{C}$, Final time; $1 \mathrm{~min}$., Rate; $15 \mathrm{deg}$./min, oven temperature; $35^{\circ} \mathrm{C}$, injection temperature; $200^{\circ} \mathrm{C}$, detector temperature; $250^{\circ} \mathrm{C}$, equilibrium time; $1 \mathrm{~min}$.

13. $\mathrm{k}_{\mathrm{obs}}$ at each temperature is obtained from the slope of the equation, $\mathrm{d}[\mathrm{THQ}] / \mathrm{dt}=\mathrm{k}_{\mathrm{obs}}[\mathrm{Q}]^{\mathrm{o}}$, assuming zero order reaction from data obtained. The activation energy, $\mathrm{E}_{\mathrm{a}}$, is calculated from the expression $\mathrm{k}_{\mathrm{obs}}=\mathrm{Ae}^{(-\mathrm{Ea} / \mathrm{RT})}$.

14. F. E. Massoth and J. S. Shabtai, "Catalysts Possessing Augmented C-O and C-N Hydrogenolysis Activity", Progress Report No. 6, PETSC Contract No. DE-FG22-83PC60812.

15. T. A. Pecoraro and R. R. Chianelli, J. Catal. (1981) 67, 430.

16. S. Harris and R. R. Chianelli, "Catalysis by Transition Metal Sulfides: The Relation between Calculated Electronic Trends and HDS Activity", J. Catal. (1984) 86, 400

17. T. G. Harvey and T. W. Matheson, "Hydrodenitrogenation Catalyzed by Zeolite Supported Ruthenium", J. Chem. Soc. Chem. Comm. (1985) 188.

18. S-I. Murahashi, Y. Imada, and Y. Hirai, "Rhodium Catalyst Hydrogenation of Quinolines and Isoquinolines under Water-Gas Shift Conditions", Bull. Chem. Soc. Jpn. (1989) 6 2, 2968.

19. M. J. Guttieri and W. F. Maier, J. Org. Chem. (1984) 49, 2875. 

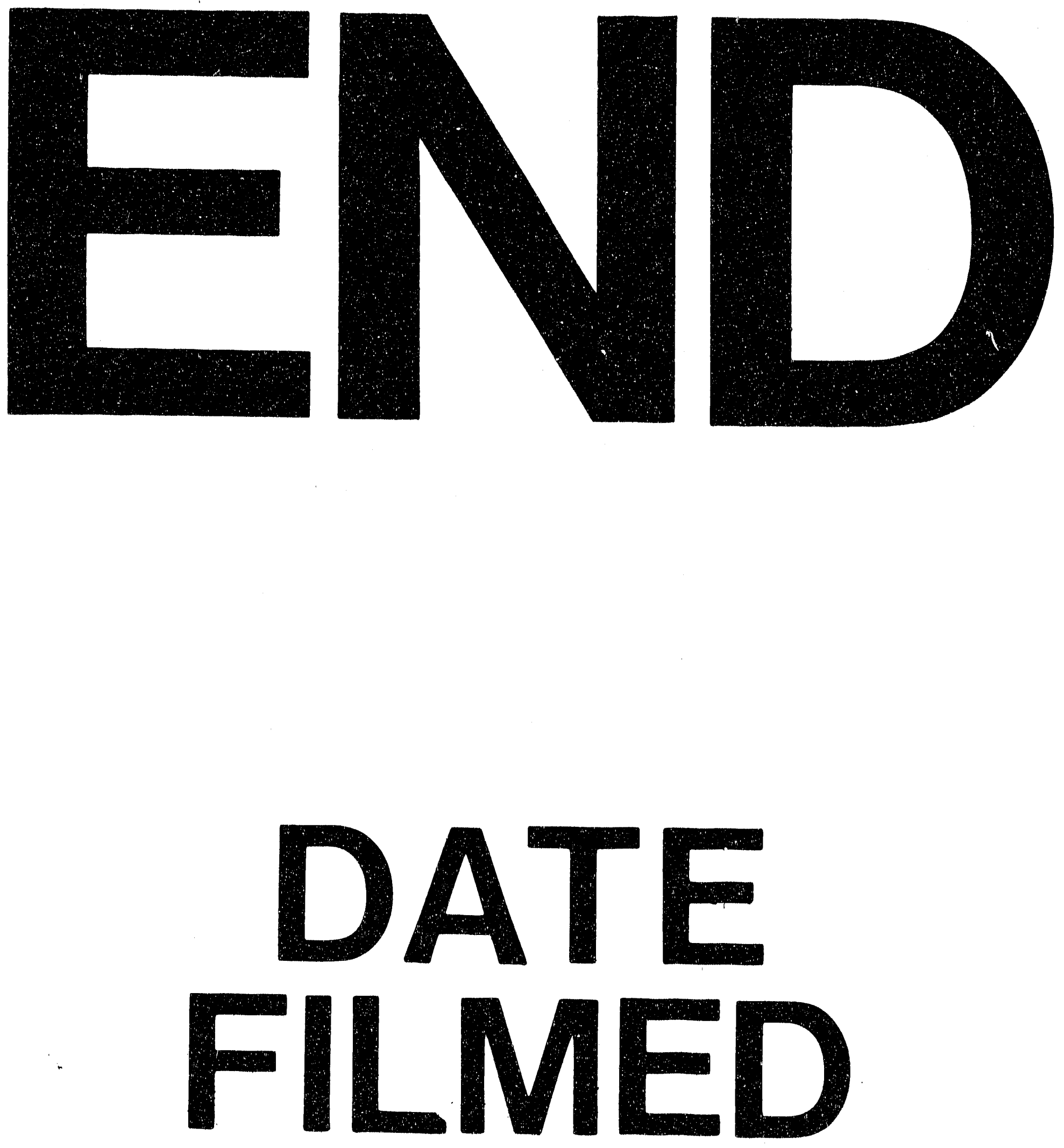

1

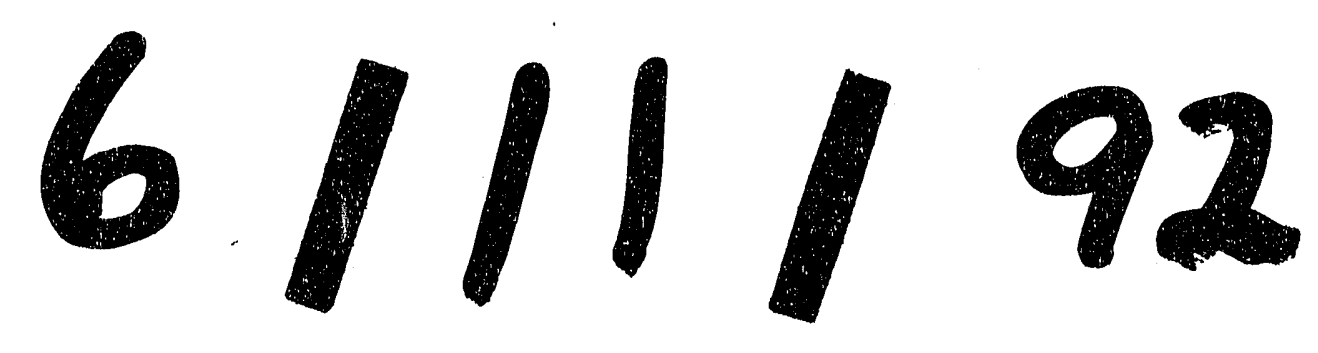


